\title{
Coronary artery to left atrium fistula requiring revascularisation: case report and literature review
}

\author{
M SWANK, DE KOEPKE \\ From the Division of Thoracic Surgery, Naval Regional Medical Center, Portsmouth, Virginia, USA
}

ABSTRACT Only 12 cases of coronary artery to left atrium fistula have been reported, with successful correction in at least seven. We describe a unique case of repair of a left main coronary artery to left atrium fistula using revascularisation with general discussion of the embryology, pathophysiology, complications, and diagnosis of these fistulae, indications for operation, and guidelines for surgical management.

Since Krause ${ }^{1}$ in 1965 first reported a fistulous communication between a coronary artery and cardiac chamber, 209 cases have been documented. ${ }^{2-5}$ There have been only 12 reported cases $(5.7 \%)$ of coronary artery to left atrium fistula, at least seven of which have been successfully corrected..$^{35-12}$ No procedure has included myocardial revascularisation. An unusual case of a large left main coronary to left atrium fistula with aneurysm formation is presented. A review of the literature reveals important features of this rare problem and provides a plan of surgical management.

\section{Case report}

The patient, a 60-year-old white woman, was first seen by a cardiologist in October 1977 . She complained of fatigue and dyspnoea on exertion but there were no definite symptoms of coronary insufficiency. Examination revealed a well-developed, well-nourished lady. Blood pressure was $130 / 100 \mathrm{~mm} \mathrm{Hg}$. Pulse rate was $80 / \mathrm{min}$ and irregularly irregular. The heart was not enlarged and there were no murmurs, but an ejection click was present along the left sternal border. There was no other abnormality.

The ECG demonstrated atrial fibrillation, left axis deviation, and left ventricular hypertrophy. Laboratory examination was normal except for elevated bilirubin $(27 \mu \mathrm{mol} / \mathrm{l}(1.6 \mathrm{mg} / 100 \mathrm{ml}))$. Chest radiography (figs 1,2 ) showed a moderately

The opinions and assertions contained in this article do not necessarily reflect the views of the Bureau of Medicine and Surgery of the Navy Department or the Naval Service at large.

Address for reprint requests: Michael Swank, Department of Surgery, Naval Regional Medical Centre, Portsmouth, Virginia 23708, USA. enlarged heart. Calcified densities overlay the cardiac silhouette in all views. Tomograms (fig 3 ) revealed a linear area of calcification connecting two densities. Cardiac catheterisation was performed. Haemodynamic data were normal without evidence of aortic stenosis or systemic hypertension. The aorta and sinuses of Valsalva were normal. A large coronary fistula arose from the left main coronary artery above the left coronary cusp. This measured $1 \mathrm{~cm}$ in diameter and passed to the right and posteriorly where it connected with an aneurysmal calcified chamber measuring 4-5 cm (fig 4). At the inferior border of the dilated chamber, a small funnel-like opening was seen, through which contrast material jetted into a normal-sized atrium (fig 5). The right and left coronary arteries were selectively studied and found to be normal.

Surgical correction was performed in January 1978. A fistulous tract, externally $1 \mathrm{~cm}$ in size, ran from the left coronary ostium to the right behind the superior vena cava and terminated in a $4-5 \mathrm{~cm}$ aneurysmal mass superior to the left atrium. Cardiopulmonary bypass was established. The fistula was dissected free and mobilised at the entrance to the left atrium. The neck of the aneurysm was closed. Two coronary bypass grafts were performed under cardioplegic arrest, one to the left anterior descending (LAD) and another to the circumflex coronary artery. The aorta was opened to expose the left coronary ostium, which measured $2 \times 2.5 \mathrm{~cm}$ The fistula arose from an aneurysmal sac which in essence was the left main coronary. The coronary ostium was closed from inside the aorta with a Dacron patch. Aortic cross-clamp time was 55 minutes. The left main coronary artery just distal to the aneurysm was suture ligated to exclude it from the vein grafts. The heart came off bypass well in atrial 


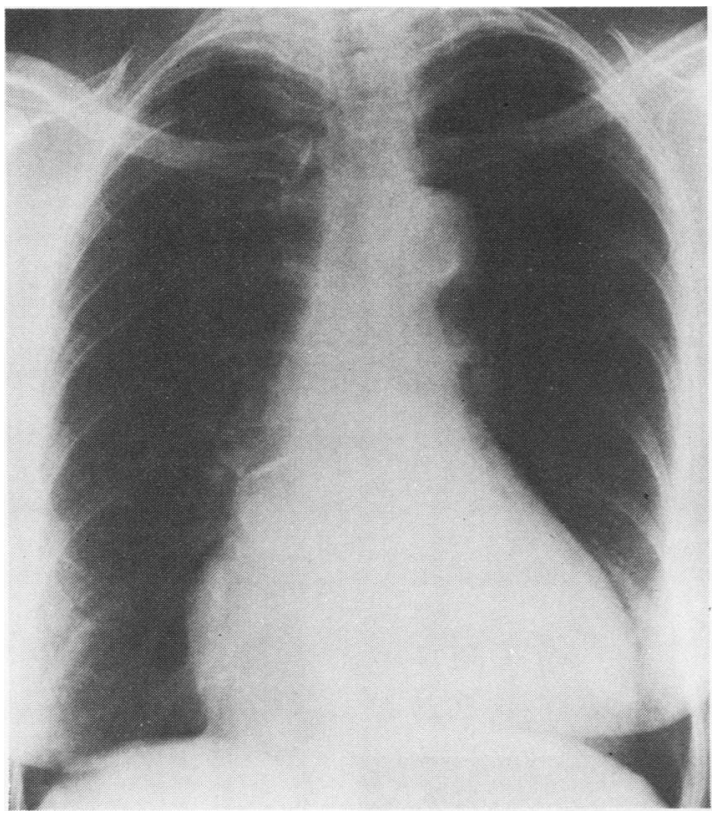

Fig 1 PA chest radiograph showing calcified densities overlying the cardiac silhouette.

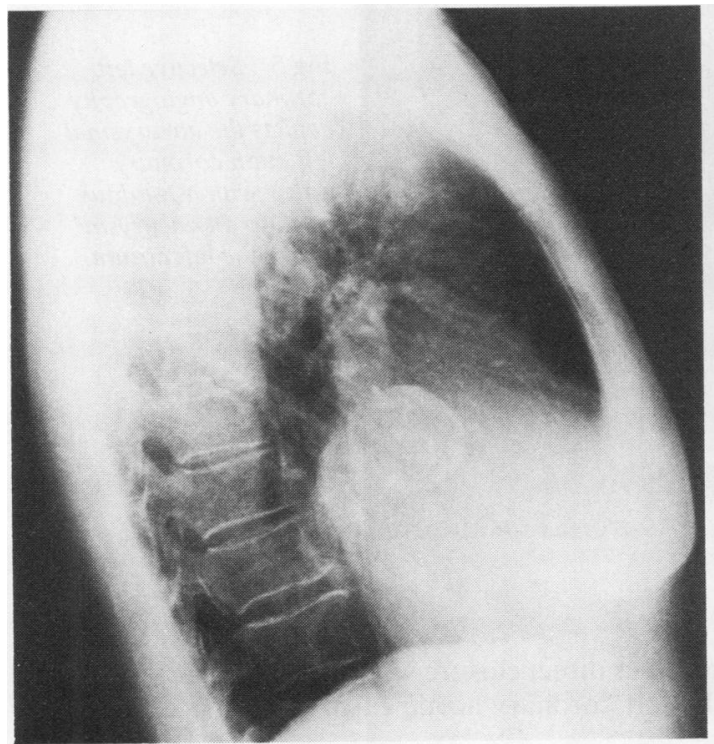

Fig 2 Lateral chest radiograph showing calcified densities overlying the cardiac silhouette.

fibrillation. Flow rates to both the LAD and circumflex were recorded at $100 \mathrm{ml} /$ minute. The postoperative course was unremarkable. Serial ECGs and cardiac enzymes demonstrated no evidence of myocardial infarction or ischaemia. She continued in atrial fibrillation, controlled with digitalis. The patient was alive and well 14 months after discharge.

\section{Discussion}

An excellent review of coronary artery to cardiac chamber fistulae was published by Rittenhouse in 1975..$^{4}$ We have confined our report to this case and a review of other cases of a fistula terminating in the left atrium.

Of the 209 reported fistulae in the English literature up to $1978,12(5.7 \%)$ terminated in the left atrium. Details of these are presented in the table. Most patients were male and ages ranged from 5 to 64 years. Five patients, including this case, presented with some evidence of cardiac failure and two patients had angina. Six patients demonstrated a continuous murmur. Electrocardiography was not diagnostic. In seven cases in which data were available, correction was performed with ligation of the origin or termination of the fistula. Three patients were alive and symptomless after operation, one had persistent failure, and a 5-yearold had a myocardial infarction and angina at 8 years of age. A 6-year-old had intermittent angina and died suddenly five years after operation.

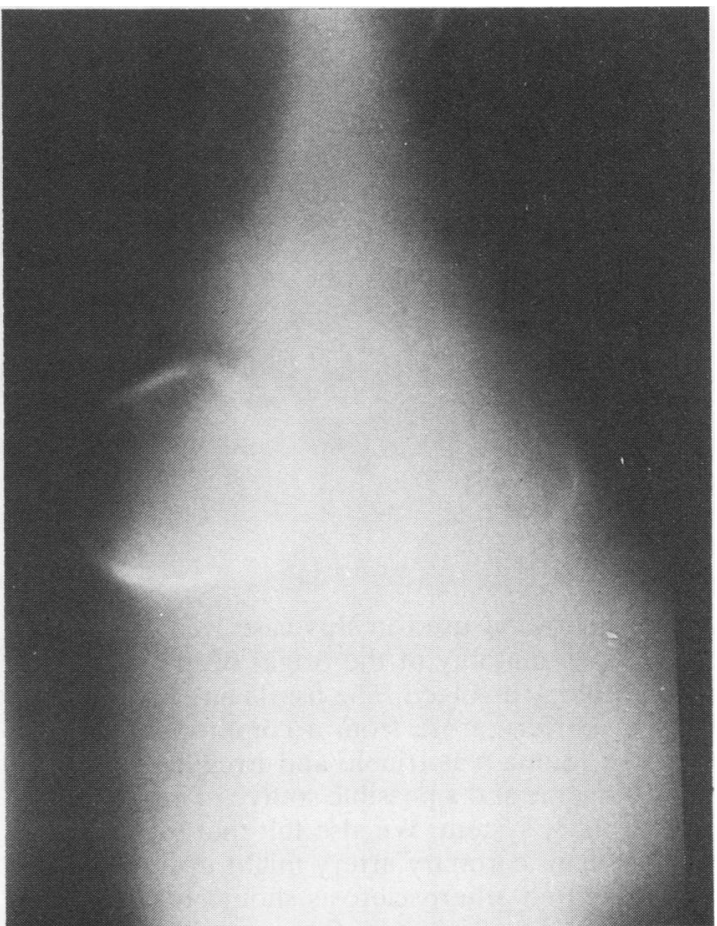

Fig 3 Tomogram showing a linear area of calcification connecting two aneurysmal masses. 


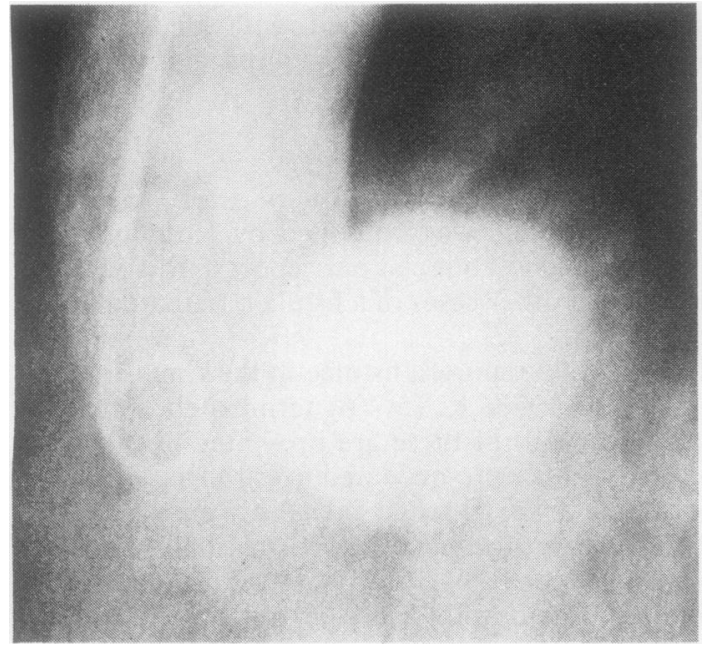

Fig 4 During angiography, dye injected into the aortic root fills a large mass with a funnel-like opening into a normal size left atrium.

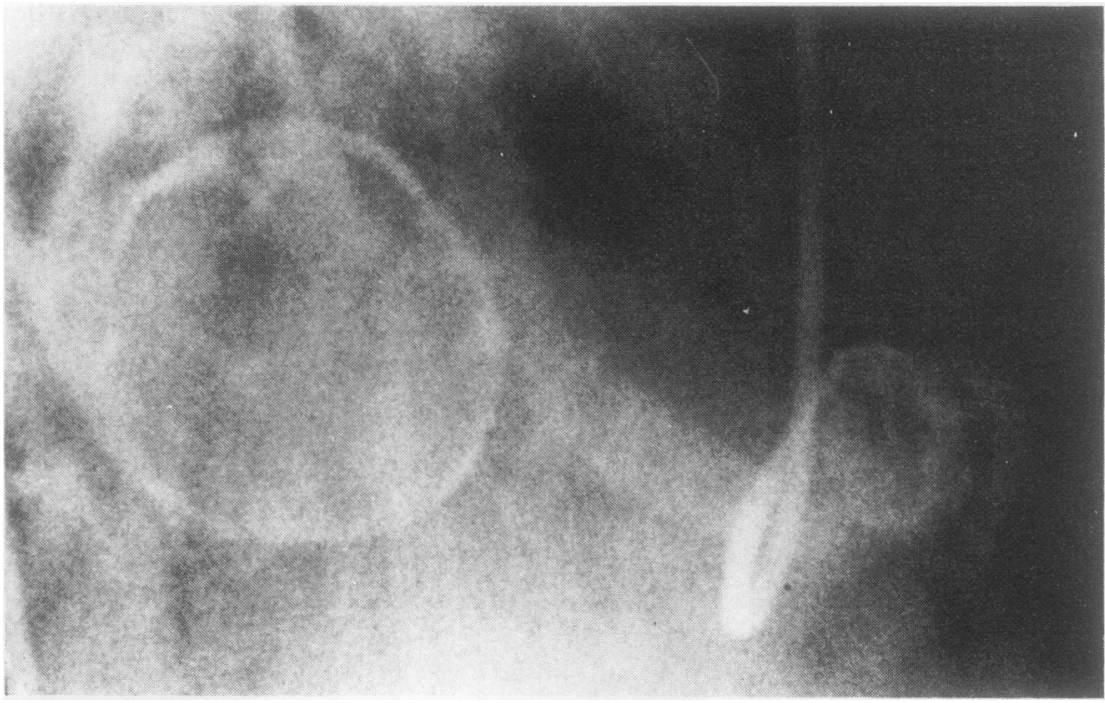

Fig 5 Selective left coronary angiography depicts the aneurysmal left main coronary artery with a fistulous track to an aneurysm above the left atrium.

The operation used in this case was dictated by the unique anatomy of the origin of the fistula and the pathology involved. The fistula and the left main coronary artery arose from a common aneurysmal sac. The intima was friable and irregular making it thrombogenic and a possible source of emboli to the left coronary system. We also felt that turbulence in the left main coronary artery might eventually lead to accelerated atherosclerosis should the aneurysm be subjected to flow from the aorta. The left main ostium was therefore obliterated with a Dacron patch as direct closure would have severely distorted the left coronary aortic cusp.

EMBR YOLOGY

The embryological formation of coronary artery to cardiac chamber fistula has been explained by Grant $^{13}$ and others. ${ }^{14}$ is During early prenatal life, intramyocardial trabecular sinusoids freely connect the heart cavity with the coronary veins and arteries. Normally the sinusoids become narrowed and persist in the adult only as thebesian vessels. If the 
Table Features of reported cases of left coronary artery to left atrium fistula

\begin{tabular}{|c|c|c|c|c|c|c|c|c|c|}
\hline Case & Age & Sex & Symptoms & Examination & $E C G$ & Origin & Termination & Operation & Results \\
\hline 1 & 10 & $\mathbf{M}$ & Dyspnoea & Murmur & Normal & LCA & LA & Proximal & Alive and well \\
\hline 2 & 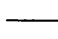 & & Data $u$ & navailable - & & & LA & Amputation & Alive and well \\
\hline $\left.\begin{array}{l}3 \\
4\end{array}\right\}$ & \multicolumn{9}{|c|}{ Data unavailable } \\
\hline 6 & 54 & $\mathbf{M}$ & Angina & \multicolumn{2}{|c|}{ Data unavailable } & - LAD & LA & None & Severe angina \\
\hline 7 & 58 & $\mathrm{~F}$ & Heart failure & MSAI & Unknown & Circumflex & LA & $\begin{array}{l}\text { Closed mitral } \\
\text { commissuro- } \\
\text { tomy }\end{array}$ & Improved \\
\hline 8 & 6 & $\mathbf{M}$ & None & Murmur & LVH & Circumflex & $\begin{array}{l}\text { LA } \\
\text { appendage }\end{array}$ & $\begin{array}{l}\text { Amputation } \\
\text { LA appendage }\end{array}$ & $\begin{array}{l}\text { Cardiomegaly, } \\
\text { angina, sudden } \\
\text { death } 5 \text { yr after op }\end{array}$ \\
\hline 9 & 64 & $\mathbf{M}$ & Heart failure & $\mathrm{CHF}$ murmur & Old infarction & RCA & LA & Proximal & Persistent failure \\
\hline 10 & 5 & $\mathbf{M}$ & Angina & Murmur & ? LVH & RCA & LA & $\begin{array}{l}\text { Proximal } \\
\text { ligation }\end{array}$ & $\begin{array}{l}\text { Postop myocardial } \\
\text { infarction, angina } \\
\text { at } 8 \mathrm{yr}\end{array}$ \\
\hline 11 & 64 & $\mathbf{M}$ & None & $\begin{array}{l}\text { Murmur, } \\
\text { arrhythmias }\end{array}$ & $\begin{array}{l}\text { Atrial fibrilla- } \\
\text { tion, old }\end{array}$ & RCA & LA & $\begin{array}{l}\text { Ligation anom } \\
\text { alous artery }\end{array}$ & $\begin{array}{l}\text {-Alive, massive } \\
\text { atriomegaly }\end{array}$ \\
\hline 12 & 6 & $\mathbf{M}$ & Dyspnoea & Murmur & Normal & LCA & $\begin{array}{l}\text { LA } \\
\text { appendage }\end{array}$ & $\begin{array}{l}\text { Ligation LA } \\
\text { appendage }\end{array}$ & Alive and well \\
\hline
\end{tabular}

$\mathrm{MS}=$ mitral stenosis; $\mathrm{AI}=$ aortic incompetence $\mathrm{CHF}=$ congestive heart failure $\mathrm{LVH}=$ left ventricular hypertrophy; LCA = left coronary artery; RCA = right coronary artery; LAD = left anterior descending coronary artery; LA = left atrium.

intramyocardial trabecular sinusoids do not close, a fistulous communication persists between coronary arteries and cardiac chamber.

An accessory coronary artery originating from a cardiac chamber or sinus of Valsalva has been proposed as the origin of some fistulae. ${ }^{16}$ This may be the explanation of the embryology of this case as the fistula was a single vessel with a single origin and termination.

\section{PATHOPHYSIOLOGY}

The haemodynamic problems and subsequent symptoms in isolated coronary artery fistulae are determined by the size of the communication and the resistance in the chamber of termination. A large shunt flow may eventually result in congestive heart failure, or the presence of cardiomegaly and electrocardiographic evidence of left ventricular hypertrophy or ischaemia may indicate early overload. Shunting of flow through the fistula and away from the myocardium, the "coronary steal" phenomenon, ${ }^{17}$ has been demonstrated by Hudspeth and Linder. ${ }^{18}$

\section{COMPLICATIONS}

About $7 \%$ of patients have chest pain consistent with angina ${ }^{3}$ and Rittenhouse reports $3 \%{ }^{4}$ with preoperative myocardial infarction. Adequate collateral circulation probably develops in these patients compensating for the possible coronary steal. Cardiac decompensation can develop, with eventual congestive heart failure, and is more common in right-sided fistulae. Subacute bacterial endocarditis was not seen in any of the patients with left-sided fistulae but does occur in about $10 \%$ of all patients. ${ }^{219-22}$ Rupture of an aneurysm associated with these fistulae is very rare. Jaffe ${ }^{23}$ has shown the potential for accelerated atherosclerosis because of intimal damage secondary to high flow.

\section{DIAGNOSIS}

Most of the patients with coronary artery to cardiac chamber fistulae are symptomless but can present with cardiac decompensation and angina. A continuous murmur in an unusual location for a patent ductus arteriosus is usually the first clue to the condition. It may be associated with left heart enlargement in fistulae to the left atrium or left ventricle. The chest radiograph may also show calcification in aneurysms associated with the fistula, as in our patient. ${ }^{2425}$ The precise diagnosis cannot be made without cardiac catheterisation and selective coronary arteriography. The origin and termination of the fistula can then be defined, together with the magnitude of shunt flow and the degree of cardiac decompensation.

INDICATIONS FOR OPERATION

In patients with angina, subacute bacterial endocar- 
ditis, congestive heart failure, or signs of increasing cardiac decompensation, surgical intervention is clearly indicated. Symptomless patients with a small shunt can be observed as demonstrated by Jaffe. ${ }^{23}$ However, others have concluded that these fistulae should be closed as the risk of operative intervention is very low. We feel that the continued threat of potential complications and circulatory overload warrants surgical treatment, especially in infants or younger patients.

\section{SURGICAL TREATMENT}

The operative approach in the patients with fistulae terminating in the left atrium was direct ligation. In previous reports, ${ }^{11} 2627$ dealing with all types of fistulae, proximal ligation has resulted in a high incidence of myocardial ischaemia. In this series, case 10 had a diaphragmatic myocardial infarction with proximal ligation of a right coronary artery to left atrial fistula and case 9 had persistent failure with possible ischaemia. It seems reasonable therefore to suggest that distal ligation with meticulous attention to myocardial blood supply is the better approach.

We feel that the surgical approach should be tailored to the anatomy of the individual patient as defined by cardiac catheterisation and selective coronary angiography. Simple ligation with or without cardiopulmonary bypass, while preserving coronary circulation, has seemed to be adequate in most circumstances. If simple ligation is the only planned procedure, myocardial ischaemia can be avoided if a temporary occlusion of the fistula is performed with constant ECG monitoring. If revascularisation is planned preoperatively, as in this case, then cardioplegic arrest can be used.

\section{RESULTS OF SURGERY}

Rittenhouse $^{4}$ found a $2 \%$ early mortality rate in all fistulae and a $3.5 \%$ incidence of postoperative myocardial infarction. In this select series, the nine patients with coronary artery to left atrial fistula for whom data are available had one myocardial infarct and no early mortality. One patient had persistent failure and another persistent angina.

The mortality is now probably even lower as angiography and surgical technique have improved. The incidence of myocardial infarction can certainly be lowered by meticulous attention to monitoring for ischaemia and the realisation that direct myocardial revascularisation may be needed.

\section{References}

' Krause W. Über den Ursprung einer accessorischen A. coronaria cordis aus der A pulmonalis. $Z$ Rat Med 1865;24:225-7.
${ }^{2}$ McNamara JJ, Gross RR. Congenital coronary artery fistula. Surgery 1969;65:59-69.

${ }^{3}$ Oldham HN, Ebert PA, Toung WG, Sabiston DC. Surgical management of congenital coronary artery fistula. Ann Thorac Surg 1971;12:503-13.

${ }^{4}$ Rittenhouse EA, Doty DB, Ehrenhaft JC. Congenital coronary artery-cardiac chamber fistula. Ann Thorac Surg 1975;20:468-87.

${ }^{5}$ Salomon J. Coronary arterioatrial fistula treated by operation. $J$ Ped Surg 1975;11:109-10.

${ }^{\circ}$ Muzen HF. Congenital cirsoid aneurysm of a coronary artery with associated arterioatrial fistula treated by operation: a case report. Ann Surg 1956;144:215-7.

${ }^{7}$ Kittle CF. In discussion of Gasul BM, Fell EH, Moreano M, Weinberg M Jr. Congenital coronary arteriovenous aneurysm. Arch Surg 1958;78:203-4.

${ }^{8}$ Abbott OA, Rivarola $\mathrm{CH}$, Logue RB. Surgical correction of coronary arterio-venous fistula. J Thorac Cardiovasc Surg 1961;42:660-72.

' Effler DB, Sheldon WC, Turner JJ, Groves LK. Coronary arteriovenous fistulas. Diagnosis and surgical management: report of 5 cases. Surgery 1967;61:41-50.

${ }^{10}$ Reed WA, Kittle CF. Congenital coronary artery fistula. Arch Surg 1966;93:772--5.

"Agusti R, Liebman J, Ankeney J, MacLeod CA, Linton DS, Wiltsie R. Congenital right coronary artery to left atrium fistula. Am J Cardiol 1967;19:428-33.

${ }^{12}$ Floyd WL, Young WG, Johnsrude JS. Coronary arterial-left atrial fistula. Case with obstruction of the inferior vena cava by a giant left atrium. Am J Cardiol 1970;25:716-22.

${ }^{13}$ Grant RT. Development of the cardiac coronary vessels in the rabbit. Heart 1926;13:261-6.

${ }^{14}$ Gosig JM. Congenital endocardial sclerosis. Bull Int Assoc Med Mus 1949;30:15-67.

${ }^{15}$ Belfet S, Gouley BA. Congenital heart disease with multiple cardiac anomalies. Report of a case showing aortic atresia, fibrous scar in myocardium and embryonal sinusoidal remains. Am J Med Sc 1932;183:458-65.

${ }^{16}$ Lester RG et al. Congenital communication of a coronary artery with a cardiac chamber of the pulmonary trunk. Circulation 1961;24:171-9.

${ }^{17}$ Dedichen H, Stalleberg K, Chappellen C Jr. Congenital coronary artery fistula. Thorax 1966;21:121-8.

${ }^{18}$ Hudspeth AS, Linder JH. Congenital coronary arteriovenous fistula. Arch Surg 1968;96:832-5.

${ }^{19}$ Gasul BM, Arcilla RA, Fell EH, Lynfield J, Bicoff JP, Luan LL. Congenital coronary arteriovenous fistula. Pediatrics 1960;25:531-60.

${ }^{20}$ Stasel HC Jr, Fenn JE. Coronary arteriovenous fistula between the left coronary artery and persistent left superior vena cava complicated by bacterial endocarditis. Ann Surg 1964;160:292-6.

${ }^{21}$ Symbas PN, Schlant RC, Hatcher CR Jr, Lindsay J. Congenita fistula of right coronary artery to right ventricle complicated by actinobacillus endarteritis. J Thorac Cardiovasc Surg 1967;53:379-84.

${ }^{22}$ Tsagaris TJ, Hecht HH. Coronary artery aneurysm and subacute bacterial endocarditis. Ann Intern Med 1962;57:116-21.

${ }^{23}$ Jaffe RB, Glancy DL, Epstein SE, Brown BG, Morros AF. Coronary artery right heart fistulae: long term observations in seven patients. Circulation 1973;47:133-43.

${ }^{24}$ Scott DH. Aneurysm of the coronary arteries. Am Heart J 1948;36:403-21.

${ }^{25}$ Valdiva E, Rowe GG, Angevine DM. Large congenital aneurysm of the right coronary artery. Arch Pathol 1957;63:168 71.

${ }^{26}$ Björk VO, Björk L. Coronary artery fistula.J Thorac Cardiovasc Surg 1965;49:921-30.

${ }^{27}$ Horiuchi T, Abe T, Tanaka S, Koyamada K. Congenital coronary arteriovenous fistulas. Ann Thorac Surg 1971;11:102-12. 